Article

\title{
Improved Electrocatalytic Activity and Durability of Pt Nanoparticles Supported on Boron-Doped Carbon Black
}

\author{
Rui Yao ${ }^{1, \dagger}$, Jun Gu ${ }^{1,2, *,+}$, Haitong He ${ }^{1}$ (D) and Tao Yu ${ }^{1,3, *}$ \\ 1 School of Physics, Nanjing University, Nanjing 210093, China; njuyr2018@163.com (R.Y.); \\ dolphinriver@smail.nju.edu.cn (H.H.) \\ 2 Nanjing Doinpower Technology Co., Ltd., Nanjing 211100, China \\ 3 National Laboratory of Solid State Microstructures, Nanjing 210093, China \\ * Correspondence: junguca@nju.edu.cn (J.G.); yutao@nju.edu.cn (T.Y.) \\ $+\quad$ R.Y. and J.G. contributed equally.
}

Received: 4 July 2020; Accepted: 27 July 2020; Published: 2 August 2020

\begin{abstract}
A facile strategy is proposed to synthesize boron-doped ECP600 carbon black (B-ECP600), and the catalyst of Pt supported on boron-doped ECP600 (Pt/B-ECP600) shows smaller particle sizes and a higher electrochemical surface area $\left(95.62 \mathrm{~m}^{2} \cdot \mathrm{gPt}^{-1}\right)$ and oxygen reduction reaction activity $\left(0.286 \mathrm{~A} \cdot \mathrm{mg}_{\mathrm{Pt}}{ }^{-1}\right.$ for mass activity; $0.299 \mathrm{~mA} \cdot \mathrm{cm}^{-2}$ for area specific activity) compared to the catalyst of Pt supported on ECP600 (Pt/ECP600). The results show that the boron doping of the carbon supports plays an important role in controlling the size and dispersion of $\mathrm{Pt}$ nanoparticles and the $\mathrm{O}_{2}$ adsorption/dissociation of the oxygen reduction reaction. A further accelerated durability test proves that boron doping can greatly enhance the stability of carbon support and thus improves the electrochemical performance of the catalyst during the long-time running. All these results suggest boron-doped carbon has great potential for application in fuel cells.
\end{abstract}

Keywords: ORR; boron doping; electrocatalyst; Pt; carbon black

\section{Introduction}

Proton exchange membrane fuel cells (PEMFCs) have wide application prospects for their high energy density and low pollution [1,2]. Pt loaded on carbon black is the most commonly used electrocatalyst for cathode oxygen reduction reaction (ORR) of PEMFCs. However, in addition to the high cost, several drawbacks of the catalyst, such as low activity and poor durability in practical applications, have limited the further commercialization of the $\mathrm{Pt} / \mathrm{C}$ catalyst $[3,4]$. Carbon hybrid materials, metal-free carbon-based materials, and alloy catalysts are considered as effective approaches to solve the above problems [5-9]. For example, doping heteroatoms such as N, P, and B into the frameworks of carbon materials can improve their electrocatalytic activity, as doped heteroatoms can break the electrical neutrality of adjacent carbon atoms and create active sites, thus facilitating the adsorption of oxygen molecules and the oxygen reduction reaction [10-12]. The advantages of doped carbon materials as the catalyst supports include promoting the dispersion of the catalyst, improving $\mathrm{Pt}$ nanoparticle adhesion, and better adsorption strength for oxygen-containing species [12-16].

Recently, a variety of studies on doped carbon materials have made some achievements. Cao et al. prepared the nitrogen and boron co-doped hollow carbon tube (NB-HCT) catalyst from the fruit fiber of platanus by a facile three-step method [17]. Tam et al. synthesized B-doped graphene quantum dots (BGQD) as a metal-free electrocatalyst for oxygen reduction reaction by carbonizing the glucose with different concentrations of boric acid through hydrothermal treatment [18]. $\mathrm{Du}$ et al. synthesized N-doped carbon-stabilized PtCo nanoparticles (PtCo@NC) via thermal 
decomposition of a Pt-incorporated Co-based zeolitic imidazolate framework (Pt@ZIF-67) [19]. Nsabimana et al. synthesized boron-doped ordered mesoporous carbons (BOMC) by a nano-casting method, using SBA-15 mesoporous silica as template, and 4-hydroxyphenylboronic acid and sucrose as boron and carbon sources, respectively [16]. Despite the progress that has been made in the research of carbon hybrid materials, the following problems still exist in the actual production or application process: there are only a few studies demonstrating the synthesis of B-doped carbon materials and their applications due to the difficulty of synthesis, the raw materials are environmentally unfriendly and unhealthy, the process is complex and not suitable for mass production, and some doped carbon materials only show good ORR activity in an alkaline environment, which is not suitable for the acidic environment of PEMFCs, and so on [15,20-22].

In this study, we doped boron into ECP600 carbon black by a simple method: Nickel was firstly loaded into carbon black, and then boron was substituted into carbon black with sodium borohydride $\left(\mathrm{NaBH}_{4}\right)$ as a structure-directing agent. Furthermore, the catalysts of Pt nanoparticles supported on ECP600 with and without boron-doping were prepared. The result of the electrochemical test shows that the platinum catalyst using B-doped ECP600 (B-ECP600) as support exhibits much higher electrocatalytic activity $\left(95.62 \mathrm{~m}^{2} \cdot \mathrm{gPt}^{-1}\right.$ of the electrochemically-active surface area (ECSA) and $0.286 \mathrm{~A} \cdot \mathrm{mg}_{\mathrm{Pt}^{-1}}{ }^{-1}$ of mass activity (MA)) and better stability than the same type of catalysts supported on ECP600 without boron-doping. In addition, X-ray powder diffraction (XRD), transmission electron microscopy (TEM), X-ray photoelectron spectroscopy (XPS), Fourier-transform infrared spectroscopy (FTIR), and the nitrogen adsorption-desorption isotherm have also been used to explain the effects of B-doped carbon blacks. Meaningfully, the above doping process is simple and easy to repeat and thus has great potential for large-scale production.

\section{Results and Discussion}

\subsection{Characterization of B-ECP600}

The XRD patterns of ECP600 and B-ECP600 are shown in Figure 1a. The XRD patterns of ECP600 and B-ECP600 both exhibit two diffraction peaks, which correspond to the (002) diffraction peak of graphite at $2 \theta$ value of ca. $25^{\circ}$ and the (100) diffraction peak at ca. $43.5^{\circ}$. Compared to the ECP600, a slight shift of the (002) diffraction peak toward the negative $2 \theta$ value can be seen from the XRD pattern of $\mathrm{B}-\mathrm{ECP} 600$, proving that the incorporation of $\mathrm{B}$ leads to the increase of interlayer spacing.

The existence of B in B-ECP600 was proved by XPS. The XPS spectra of B1s narrow-scans of the B-ECP600 are shown in Figure 1b. By analyzing the detailed B1s XPS spectra, we could find a peak at $191.9 \mathrm{eV}$, corresponding to the oxidized state of $\mathrm{B}$. The atomic concentrations of $\mathrm{B}$ and $\mathrm{Ni}$ in the B-ECP600 were $0.5 \%$ and $0.09 \%$, respectively, as estimated from the intensities of the corresponding XPS peaks. Figure 1c shows the C1s XPS spectrum of the B-ECP600. We could accordingly deconvolve $\mathrm{C} 1$ s peak into 3 peaks at 283.8, 285.4, and $289.2 \mathrm{eV}$, corresponding to $\mathrm{C}=\mathrm{C} / \mathrm{C}-\mathrm{C}$ (carbon backbone), $\mathrm{C}-\mathrm{O}$ (epoxy and/or alkoxy), and COOR (carboxylic and/or lactones), respectively [23]. The results of the FTIR (Figure 1d) also show that B-ECP600 has varied oxygen-containing groups.

The nitrogen adsorption-desorption isotherms and the corresponding pore size distribution curves of B-ECP600 and ECP600 are presented in Figure 1e,f, respectively. It can be seen from Figure 1a that the nitrogen adsorption-desorption isotherms of B-ECP600 and ECP600 exhibit type IV curves with the hysteresis loops at lower $(0.4-0.8)$ and higher $(0.8-1.0)$ relative pressures, which indicate the existence of mesopores and macropores [24]. As shown in Figure 1f, the primary pore size of B-ECP600 is $3.66 \mathrm{~nm}$, while ECP600 displays a primary pore size of $3.80 \mathrm{~nm}$. The Brunauer-Emmett-Teller (BET) surface area of B-ECP600 and ECP600 were calculated to be 957.5 and $1416.5 \mathrm{~m}^{2} \cdot \mathrm{g}^{-1}$, respectively. A lower BET surface area indicates that the mesopores and micropores in B-ECP600 have been collapsed, and thus, the conductivity was improved [25]. The total pore volumes are 1.75 and $2.07 \mathrm{~cm}^{3} \cdot \mathrm{g}^{-1}$ for B-ECP600 and ECP600, respectively. 


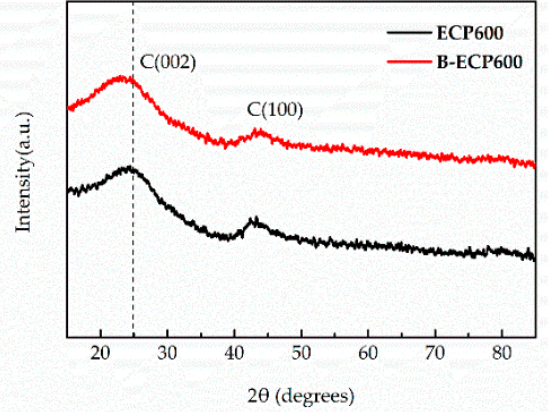

(a)

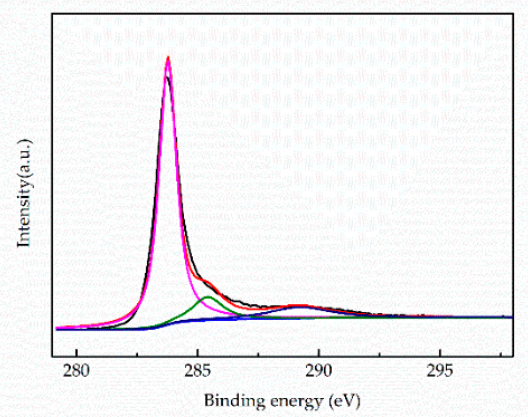

(c)

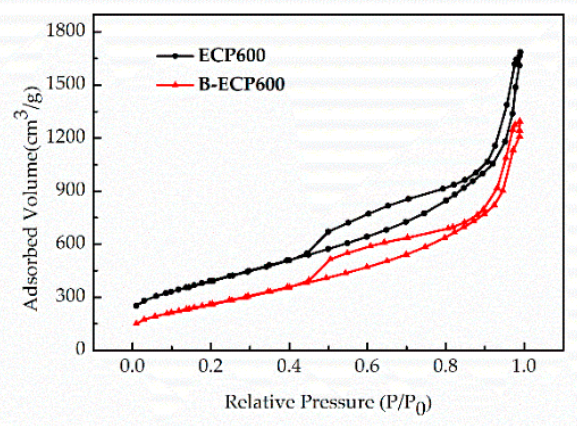

(e)

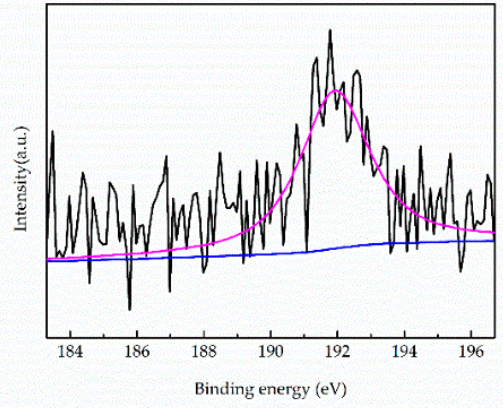

(b)

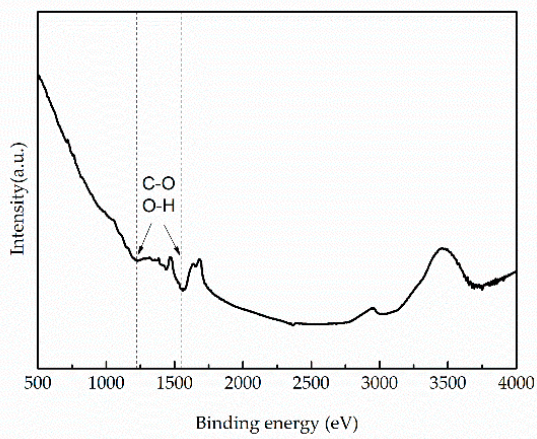

(d)

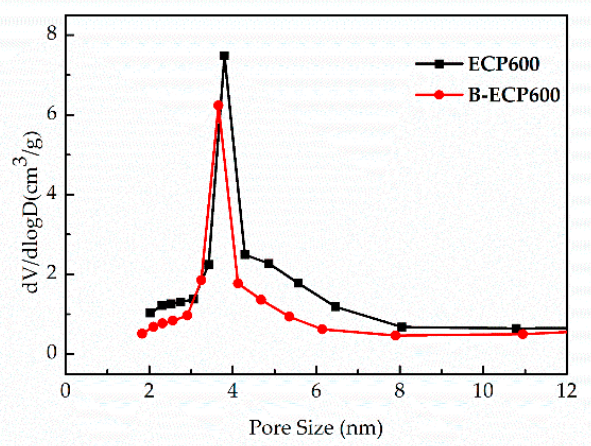

(f)

Figure 1. (a) XRD results of ECP600 and B-ECP600; (b) B1s; (c) C1s narrow-scan of B-ECP600; (d) FTIR spectrum of B-ECP600; (e) nitrogen adsorption-desorption isotherms; and (f) pore size distributions of ECP600 and B-ECP600.

The morphology and structure of ECP600 and B-ECP600 were characterized by TEM. The TEM image of ECP600 (Figure 2a) shows the branched chain structure composed of carbon nanospheres. Figure $2 b$ shows the TEM image of B-ECP600 without obvious carbon nanospheres. It can be seen that the structure of B-ECP600 has become much thinner and exhibits a partial sheet-like feature. This structural change is due to the $\mathrm{NaBH}_{4}$ as a structure-directing agent [26]. This unique structure of B-ECP600 can provide more defect sites for platinum particles in the process of catalyst preparation and thus improve the electrochemical performance of the catalysts. 

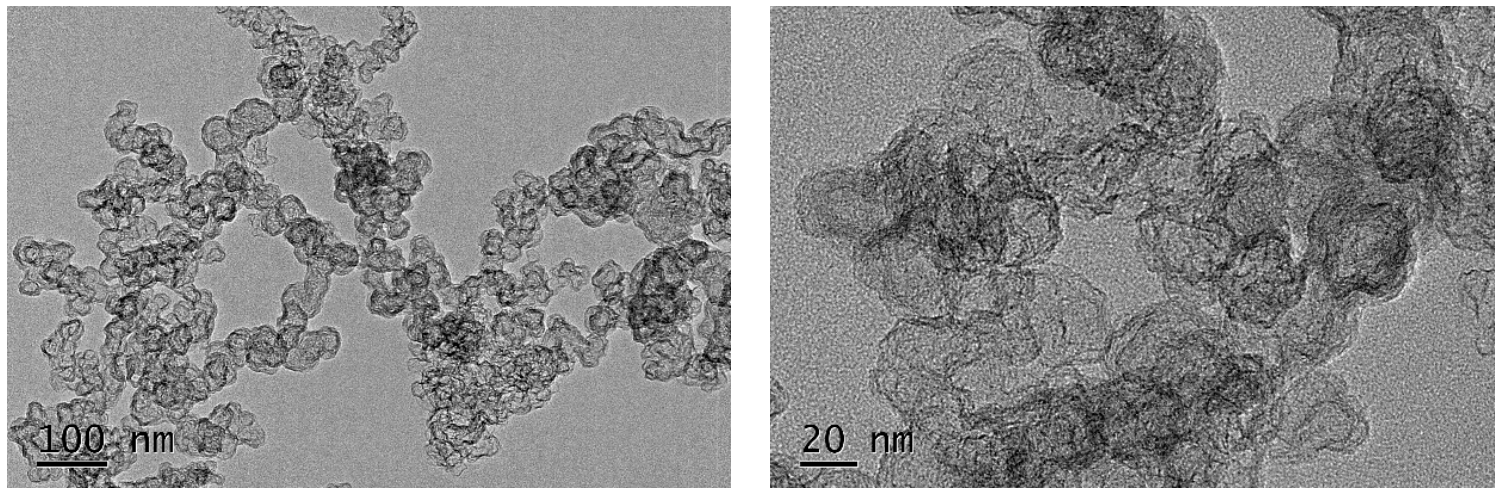

(a)
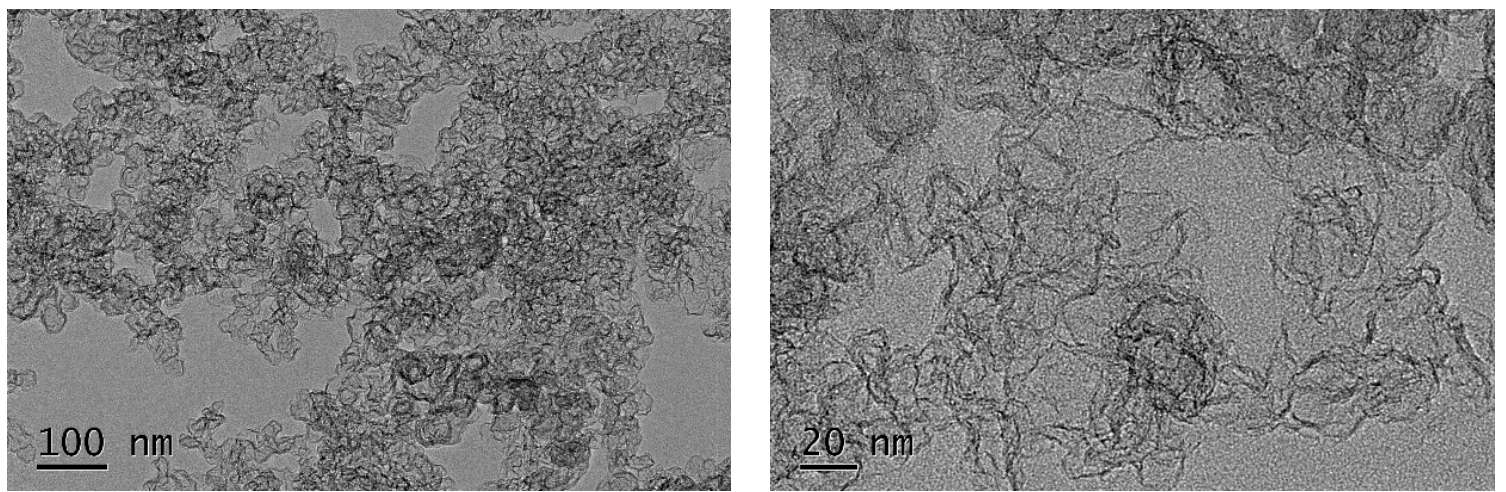

(b)

Figure 2. TEM images of (a) ECP600 and (b) B-ECP600.

The proposed mechanism for the formation of B-ECP600 is schematically presented in Scheme 1. First, $\mathrm{Ni}$ atoms were loaded on ECP600 under a temperature of $170^{\circ} \mathrm{C}$. Especially at high temperature, ethylene glycol, as a relatively gentle reducing agent, could keep the reaction rate in a suitable range, so that $\mathrm{Ni}$ atoms could be more evenly dispersed on carbon black, which was beneficial to the subsequent boron doping. At the same time, the whole reduction process was carried out in nitrogen atmosphere, which could prevent the oxidation of the reduced Ni under high temperature. On the one hand, the $\mathrm{Ni}(0)$ supported on ECP600 could catalyze the decomposition of the NaBH4 into solid $\mathrm{B}(\mathrm{s})$ [27]. The generated $\mathrm{B}(\mathrm{s})$ underwent an alloying process immediately with the active $\mathrm{Ni}(0)$ to form amorphous Ni-B alloys and then were further oxidized by oxygen in the air [28]. On the other hand, $\mathrm{NaBH} 4$ can be hydrated into $\mathrm{BO}(\mathrm{OH}) 2$, which exhibits triangle plane symmetry. The hydroxyl groups of $\mathrm{BO}(\mathrm{OH}) 2$ could condense with hydroxyl groups from carbon nanospheres. Thus, the carbon nanospheres were interlinked by boron-oxygen-carbon bonds and finally formed the boron-doped carbon [23]. 


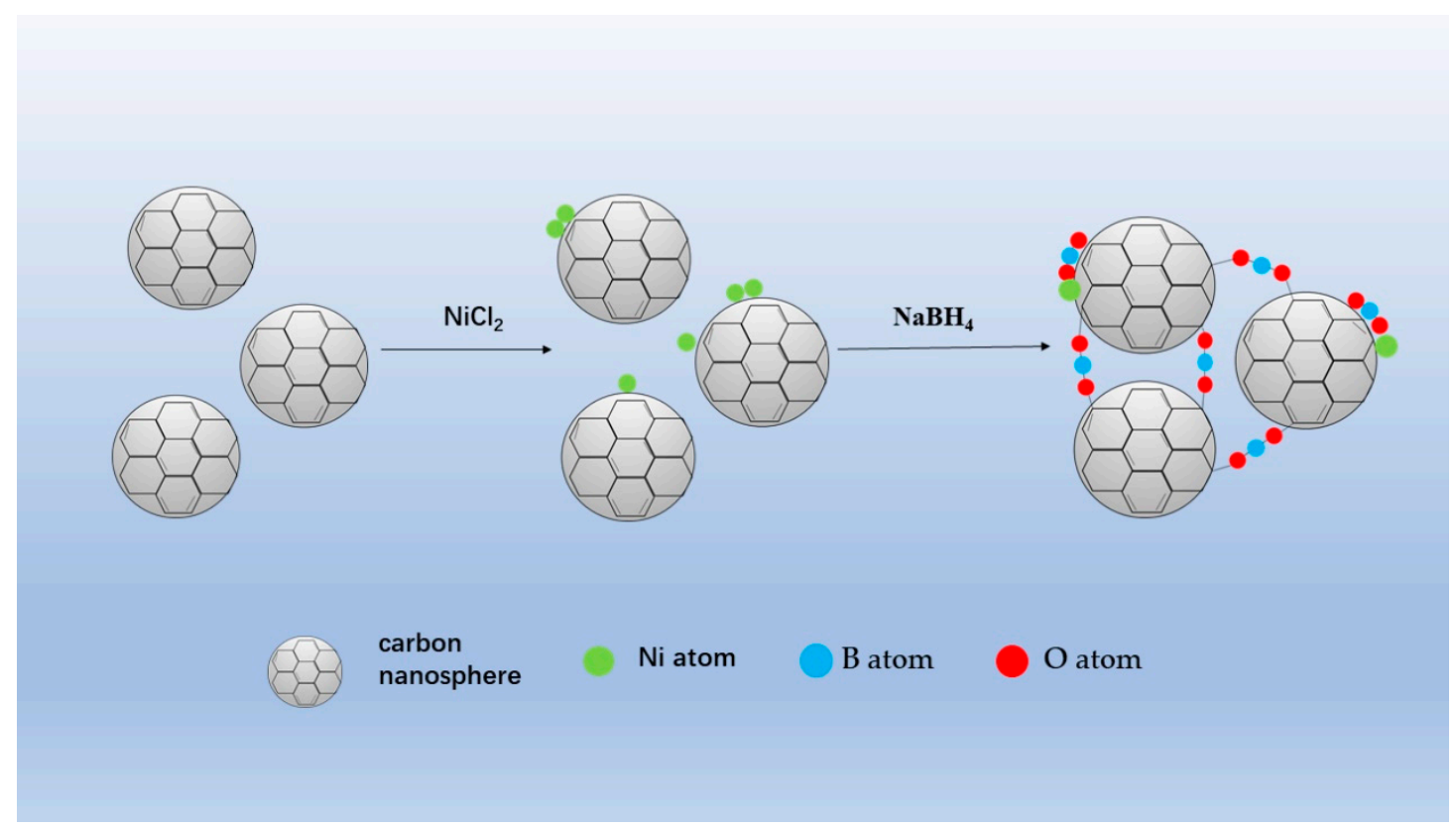

Scheme 1. Schematic representation of the formation mechanism of B-ECP600.

\subsection{Characterization of $P t / B-E C P 600$}

The structural characterization and the Pt particle size distributions of the Pt/ECP600 and Pt/B-ECP600 catalysts are shown in Figure 3. By comparing the TEM images in Figure 3a,b, we can find that Pt nanoparticles tend to aggregate to form large particle clusters on the ECP600 surface, while the Pt nanoparticles on B-ECP600 are uniformly distributed and exhibit good dispersion. It can be seen from the histograms in Figure 3c,d that the average diameter of $100 \mathrm{Pt}$ particles in Pt/ECP600 was $2.90 \mathrm{~nm}$ and that of 100 particles in Pt/B-ECP600 was $2.19 \mathrm{~nm}$, which is consistent with the results from the analysis of the TEM image. B-ECP600 has more defect sites, which provides a strong interaction and anchoring location for nonuniform nucleation of $\mathrm{Pt}$, which is one of the reasons for the high dispersion of Pt/B-ECP600 [16]. The smaller particle size and better dispersion of Pt/B-ECP600 may contribute to higher Pt utilization and better electrochemical performance compared to Pt/ECP600 [29].
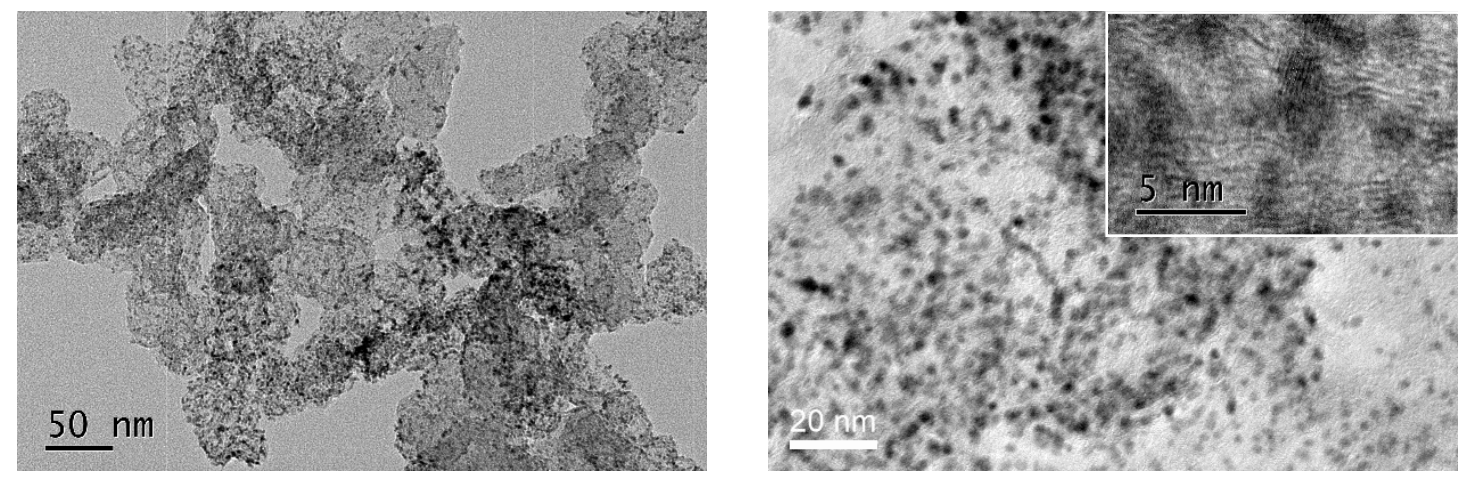

(a)

Figure 3. Cont. 

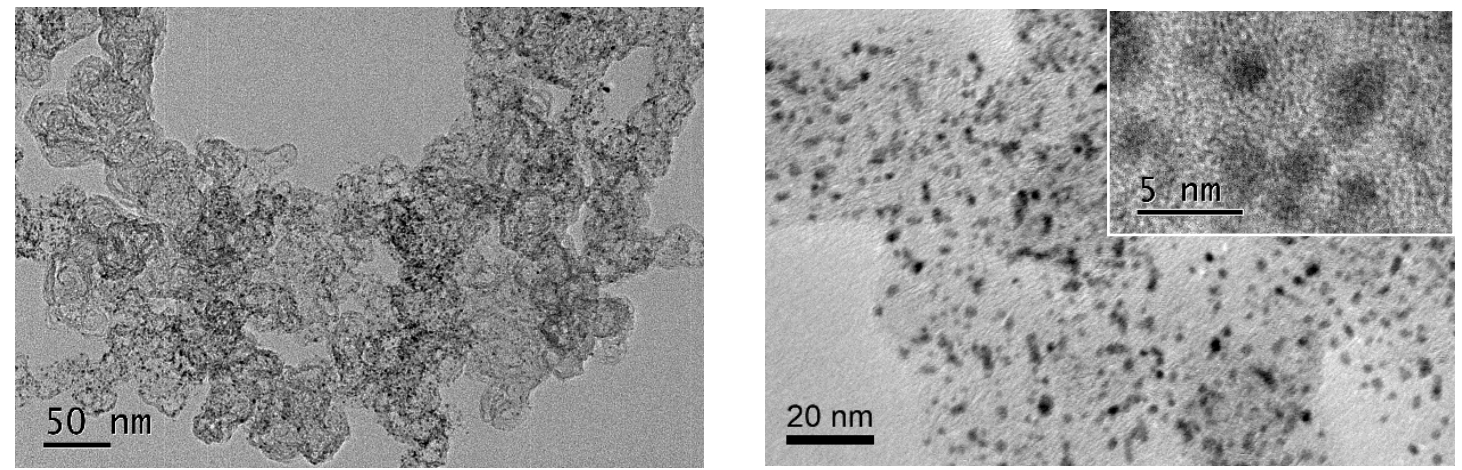

(b)

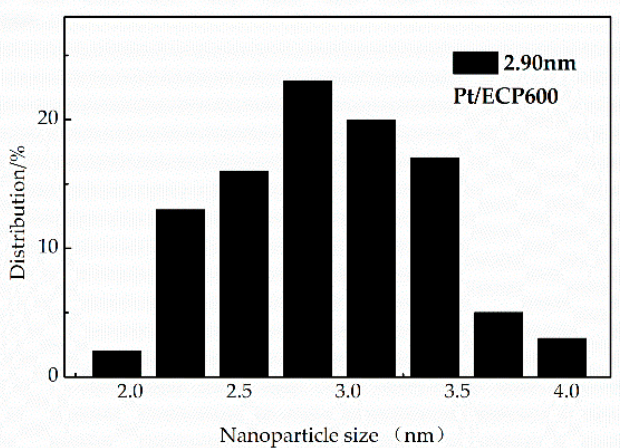

(c)

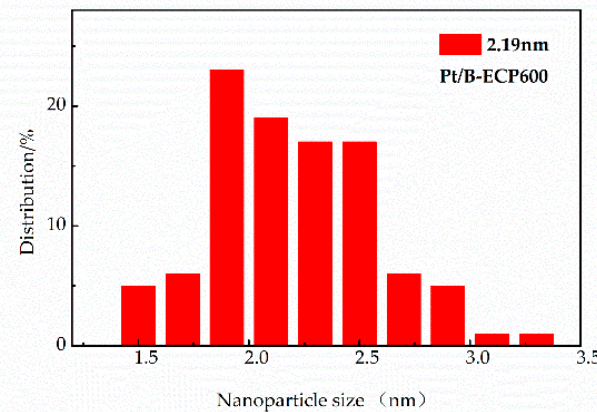

(d)

Figure 3. TEM images for (a) Pt/ECP600 and (b) Pt/B-ECP600; and particle size distributions for (c) $\mathrm{Pt} / \mathrm{ECP} 600$ and (d) Pt/B-ECP600.

The detailed Pt4f XPS spectra of the Pt/B-ECP600 sample are shown in Figure 4a. It is clearly shown that there are two peaks corresponding to $\mathrm{Pt}_{4} \mathrm{f}_{7 / 2}$ and $\mathrm{Pt} 4 \mathrm{f}_{5 / 2}$, which are evident for the presence of $\mathrm{Pt}$ nanoparticles on B-ECP600. The XRD patterns of the prepared Pt/ECP600 and Pt/B-ECP600 are shown in Figure $4 \mathrm{~b}$. Both samples show the (002) plane of carbon at $2 \theta$ value of ca. $25^{\circ}$. The characteristic diffraction peaks located at $2 \theta$ values of around $39.8^{\circ}, 46.3^{\circ}$, and $67.6^{\circ}$ correspond to the (111), (200), and (220) planes of $\mathrm{Pt}$, suggesting both catalysts display the characteristics of the $\mathrm{Pt}$ face-centered cubic (fcc) structure. The XRD pattern of Pt/B-ECP600 also shows that no PtNi alloy was formed, despite the addition of nickel in the preparation process. By analyzing XRD patterns with the Bragg formula, we found that the lattice spacing of Pt/ECP600 and Pt/B-ECP600 was calculated to be 0.225 and $0.226 \mathrm{~nm}$, which agrees well with the result of TEM.

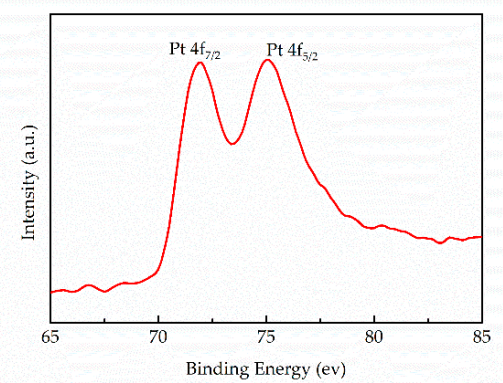

(a)

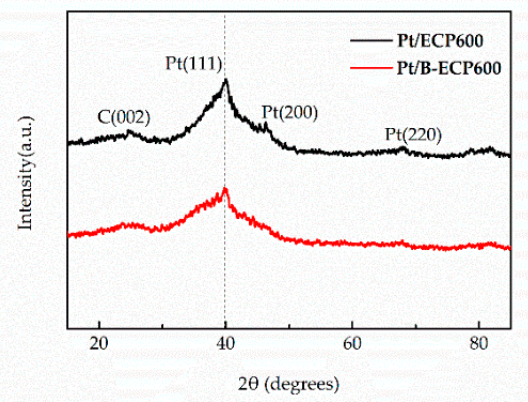

(b)

Figure 4. (a) XPS patterns of Pt 4f for Pt/B-ECP600; and (b) XRD results of ECP600 and B-ECP600. 


\subsection{Electrochemical Properties of Pt/B-ECP600}

$\mathrm{Pt} / \mathrm{ECP} 600, \mathrm{Pt} / \mathrm{B}-\mathrm{ECP} 600$, and B-ECP600 were characterized electrochemically in N2-saturated $0.1 \mathrm{M} \mathrm{HClO}_{4}$ solution at a sweep rate of $50 \mathrm{mV} / \mathrm{s}$ (Figure $5 \mathrm{a}$ ). The ECSAs of Pt/B-ECP600 and Pt/ECP600 were 95.62 and $76.57 \mathrm{~m}^{2} \cdot \mathrm{gPt}^{-1}$, respectively, calculated by integrating the underpotentially deposited hydrogen adsorption charge and normalizing with scan rate, Pt loading, and the charge value of $210 \mu \mathrm{C} \cdot \mathrm{cm}^{2}$ for the Pt surface. The higher ECSA of Pt/B-ECP600 is due to the relatively smaller particle size and uniform deposition of Pt nanoparticles on B-ECP600. As seen in Figure 5a, the maximum of the oxide reduction peak in the cathodic sweep of Pt/B-ECP600 is slightly more negative than that of the Pt/ECP600, which is consistent with the general belief that smaller Pt particles lead to a negative shift in peak potential for the reduction of the oxygenated species [30,31]. The negative shift of reduction peak of Pt/B-ECP600 also suggests an advanced electrocatalytic activity of the Pt/B-ECP600 toward ORR compared with Pt/ECP600. To better understand the characteristics of catalysts supported on B-doped ECP600, the electrocatalytic behavior of Pt/B-ECP600 and Pt/ECP600 was studied by investigating their electrocatalytic activity in the oxygen reduction reaction. Figure $5 \mathrm{~b}$ shows the linear sweep voltammetry (LSV) polarization curves of two prepared catalysts in $\mathrm{O}_{2}$-saturated $0.1 \mathrm{M} \mathrm{HClO}_{4}$ solutions at the temperature of $30^{\circ} \mathrm{C}$. The ORR half-wave potential of Pt/B-ECP600 was about $0.891 \mathrm{~V}$ compared to the $0.878 \mathrm{~V}$ of Pt/ECP600, indicating the improved activity of Pt/B-ECP600. The mass activity (MA) and area specific activity (SA) of Pt/B-ECP600 were calculated to be $0.286 \mathrm{~A} \cdot \mathrm{mg}_{\mathrm{Pt}}{ }^{-1}$ and $0.299 \mathrm{~mA} \cdot \mathrm{cm}^{-2}$, respectively, by normalizing the kinetic current at $0.9 \mathrm{~V}$ with the mass and the ECSA of the Pt on the GC electrode. The MA and SA of Pt/ECP600 were $0.217 \mathrm{~A} \cdot \mathrm{mg}_{\mathrm{Pt}}{ }^{-1}$ and $0.283 \mathrm{~mA} \cdot \mathrm{cm}^{-2}$, respectively, as shown in Table 1 . For comparison, He et al. have prepared boron-doped $\mathrm{Pt} / \mathrm{C}$ catalyst by adding doped boron into commercial $\mathrm{Pt} / \mathrm{C}(20 \mathrm{wt} \%$, JM) catalyst and improved activities (ECSA went from 71 to $73 \mathrm{~m}^{2} \cdot \mathrm{gPt}^{-1}$; MA (@0.95V) went from 0.050 to $0.150 \mathrm{~A} \cdot \mathrm{mg}_{\mathrm{Pt}^{-1}}$ ) [28]. The electrochemical performances of the catalysts were greatly improved by boron doping.

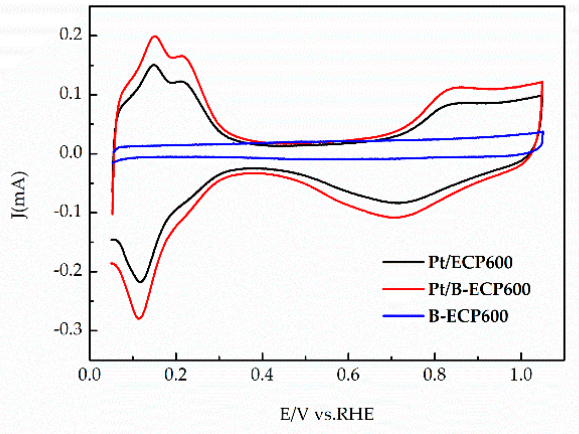

(a)

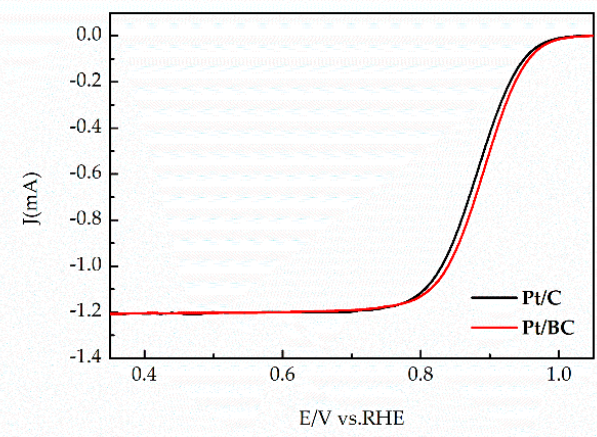

(b)

Figure 5. Electrocatalytic properties of the prepared catalysts: (a) Cyclic voltammogram (CV) curves and (b) linear sweep voltammetry (LSV) polarization curves of Pt/B-ECP600 and Pt/ECP600.

Table 1. The electrochemically-active surface area (ECSA), mass activity (MA), and area specific activity (SA) of Pt/ECP600 and Pt/B-ECP600.

\begin{tabular}{cccc}
\hline RDE TESTING & ECSA $\left(\mathbf{m}^{\mathbf{2}} \cdot \mathbf{g}_{\mathbf{P t}}{ }^{-\mathbf{1}}\right)$ & MA $\left(\mathbf{A} \cdot \mathbf{m g}_{\mathbf{P t}}{ }^{-\mathbf{1}}\right)$ & $\mathbf{S A}\left(\mathbf{m A} \cdot \mathbf{c m}^{-\mathbf{2}}\right)$ \\
\hline Pt/ECP600 & 76.57 & 0.217 & 0.283 \\
Pt/B-ECP600 & 95.62 & 0.286 & 0.299 \\
\hline
\end{tabular}

The result of XRD suggests that the enhancement of ORR activities of Pt/B-ECP600 is not due to the PtNi alloy effect. Owing to the smaller electronegativity of $\mathrm{B}$, boron doping is favorable to capture the $\mathrm{O}_{2}$ molecules [12]. However, it can be seen from Figure 6a that the B-ECP600 exhibits poor activity in acidic media, indicating that B-ECP600 might not be oxophilic enough to initiate chemisorption of $\mathrm{O}_{2}$. Previous studies suggest that boron oxide could facilitate $\mathrm{O}_{2}$ adsorption and 
weaken $\mathrm{O}$ and $\mathrm{OH}$ binding energy on $\mathrm{Pt}(111)$ to a respective optimal range of better electrocatalysis for ORR $[8,28,32,33]$. Therefore, the enhancement of ORR activities of Pt/B-ECP600 is considered to be due to the electronic effect of B-ECP600 on the Pt-O and Pt-OH chemical bonding, which is implemented by the electron-deficient boron oxide dominating electron transfer [28]. On the other hand, the spillover effect [34] may also have played an important role in improving ORR performance of Pt/B-ECP600: Due to the oxyphilicity of boron dopant on B-ECP600 supports [12], a part of adsorbed oxygen atoms dissociated from $\mathrm{O}_{2}$ molecules on $\mathrm{Pt}$ may be transferred to the adjacent $\mathrm{B}$ atoms and further reduced to $\mathrm{H}_{2} \mathrm{O}$. The analyses above suggest that the B-ECP600 has a synergetic coupling effect in the ORR electrocatalysis, and in some way, boron on B-ECP600 has taken part in the ORR and thus increased the overall ORR performance, as shown in Scheme 2.

Furthermore, in order to compare the stability of carbon supports, we assessed the long-term durability of the Pt/B-ECP600 and the Pt/ECP600 by an accelerated durability test (ADT) under a scanning rate of $100 \mathrm{mV} \cdot \mathrm{s}^{-1}$ from 1.0 to $1.6 \mathrm{~V}$ (vs. reversible hydrogen electrode (RHE)) in $0.1 \mathrm{M}$ $\mathrm{HClO}_{4}$. We compared the ECSAs of Pt/B-ECP600 and Pt/ECP600, respectively, after $5 \mathrm{~K}$ cycles of ADTs, because the ECSA of catalysts is greatly affected by the carbon supports. It can be seen from Figure $6 \mathrm{a}-\mathrm{c}$ that both as-prepared catalysts exhibit the decrease of ECSA during the ADT, while the ECSA after the ADT of Pt/B-ECP600 is still much higher than that of Pt/ECP600. As shown in Figure 6d, the ECSA of Pt/B-ECP600 after the ADT was calculated to be $62.68 \mathrm{~m}^{2} \cdot \mathrm{gPt}_{\mathrm{Pt}}^{-1}$, exhibiting a loss of $34.4 \%$. In contrast, the ECSA of Pt/ECP600 after the ADT was $44.28 \mathrm{~m}^{2} \cdot \mathrm{g}_{\mathrm{Pt}}{ }^{-1}$ with a drop of $42.2 \%$. After a relatively high potential range ADT, the main causes of ECSA loss are the aggregation and falling off of Pt due to corrosion of carbon support [35,36]. The result of ADTs indicates that the B-ECP600 has better corrosion resistance compared with the ECP600. It can be seen from Figure 6a,b that the hydrogen adsorption/desorption peaks near $0.27 \mathrm{~V}$ of Pt/B-ECP600 and Pt/ECP600, and both become more pronounced after the ADT, suggesting that the particle size of the two samples has been increased after ADTs [31]. Figure 7 shows the TEM images of the two catalysts after the ADT. Partial Pt nanoparticles of Pt/ECP600 were aggregated after the ADT, while the Pt nanoparticles of Pt/B-ECP600 still maintained good dispersion and small size. As calculated from the TEM images, the average particle size of Pt/B-ECP600 changed from 2.19 to $2.48 \mathrm{~nm}$, while the average particle size of Pt/ECP600 changed from 2.90 to $3.25 \mathrm{~nm}$. In addition, the MA of Pt/B-ECP600 after the ADT was calculated to be $0.230 \mathrm{~A} \cdot \mathrm{mg}_{\mathrm{Pt}}{ }^{-1}$, still much higher than that of Pt/ECP600 $\left(0.180 \mathrm{~A} \cdot \mathrm{mg}_{\mathrm{Pt}}{ }^{-1}\right)$. These results demonstrate that, as the support of catalysts, B-ECP600 is remarkably durable compared to ECP600, which suggests using B-ECP600 as support for Pt catalysts is a promising way to improve the durability of the catalysts.

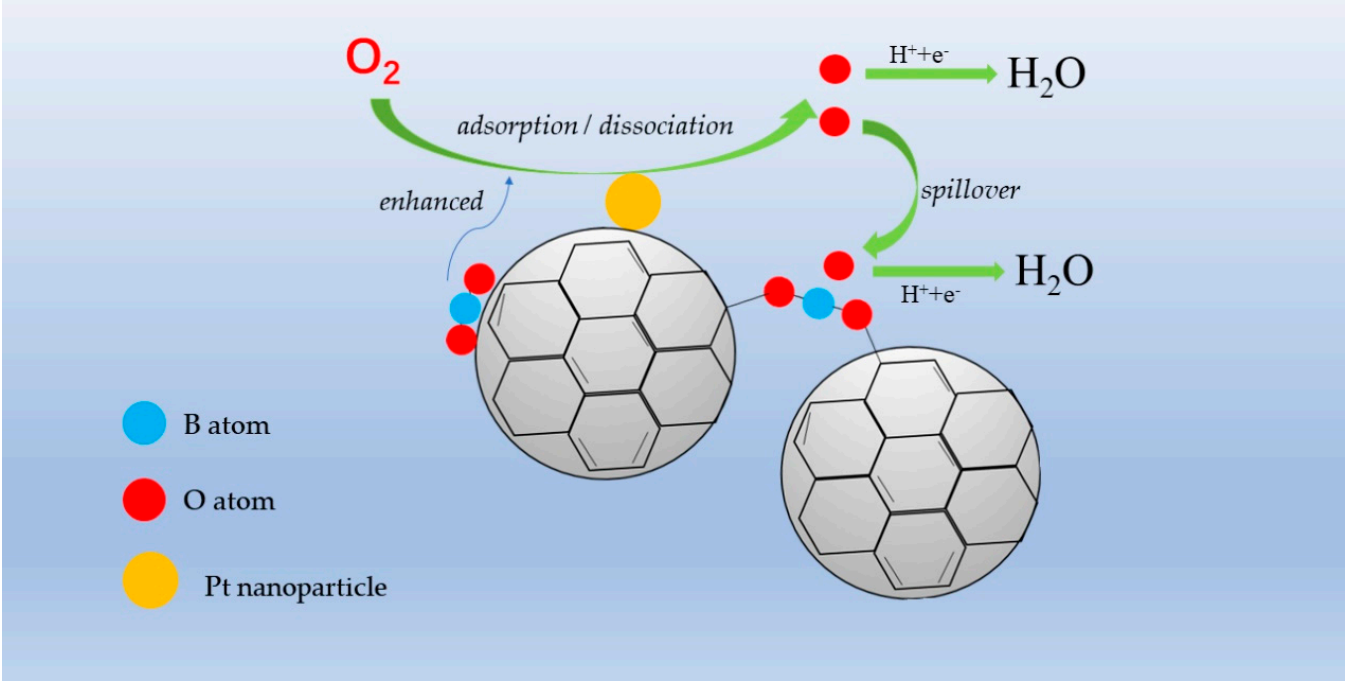

Scheme 2. Mechanism for the improved electrochemical activity. 


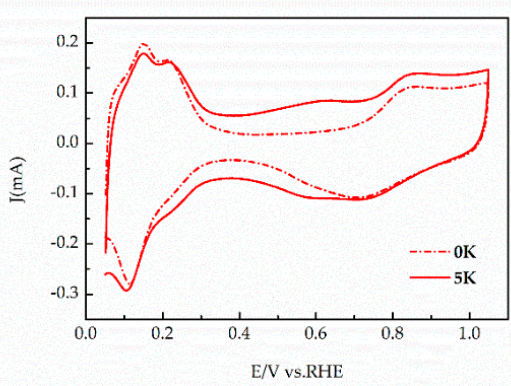

(a)

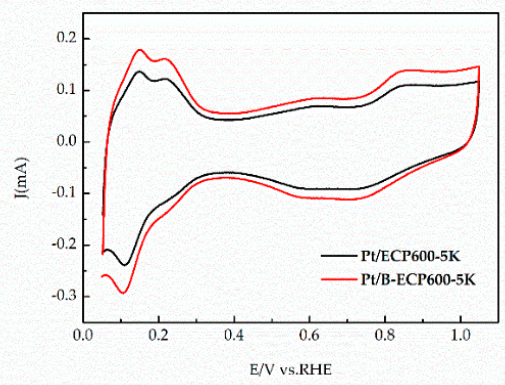

(c)

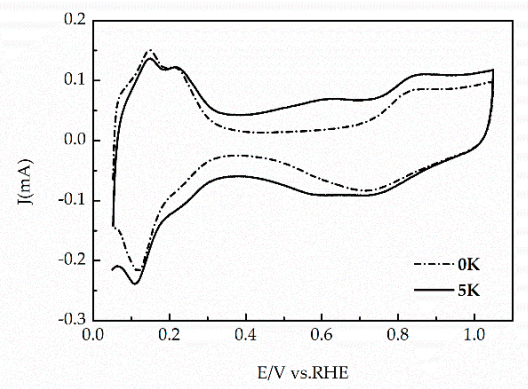

(b)

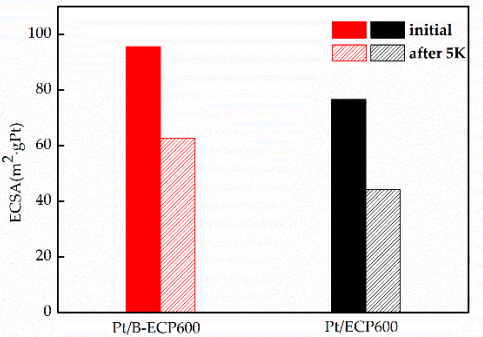

(d)

Figure 6. Electrocatalytic durability of carbon supports. CV curves of (a) Pt/B-ECP600 and (b) Pt/ECP600 before and after $5 \mathrm{~K}$ cycles of accelerated durability tests (ADTs); (c) CV curves of Pt/B-ECP600 and Pt/ECP600 after $5 \mathrm{~K}$ cycles of ADTs; and (d) ECSAs of Pt/B-ECP600 and Pt/ECP600 before and after $5 \mathrm{~K}$ cycles of ADTs.
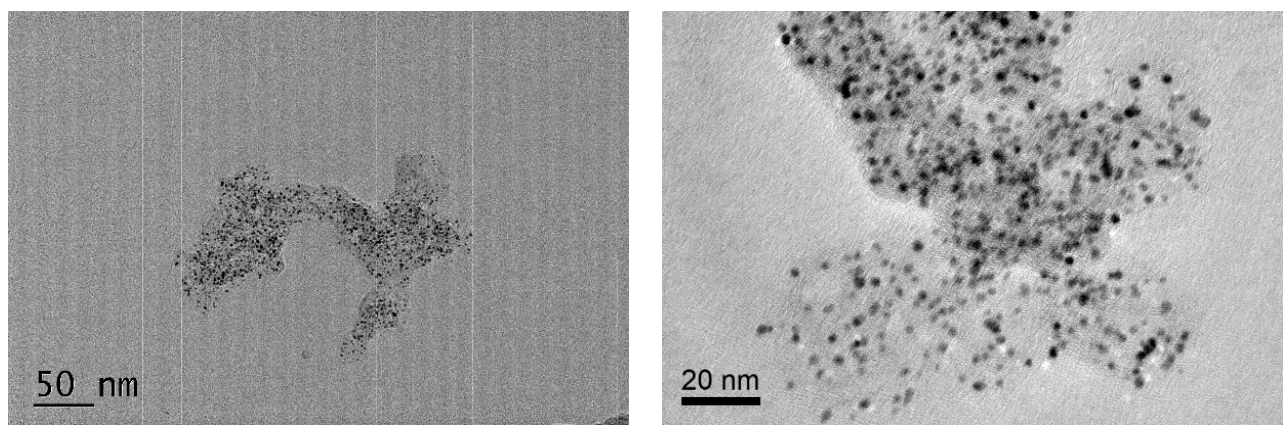

(a)
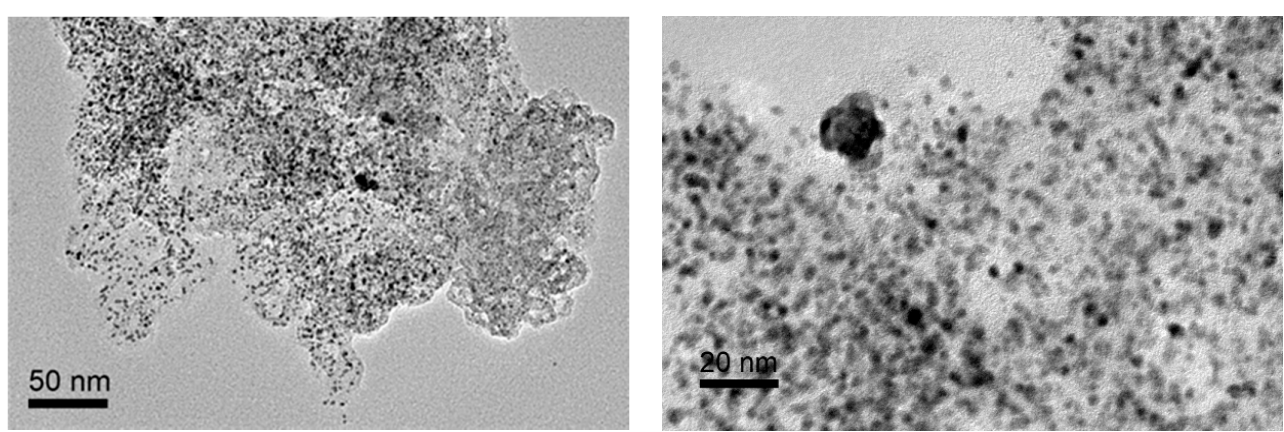

(b)

Figure 7. TEM images of (a) Pt/B-ECP600 and (b) Pt/ECP600 after 5K cycles of ADTs. 


\section{Materials and Methods}

\subsection{Chemicals}

Carbon black (Ketjenblack ECP600JD) was obtained from Lion Corporation (Japan). Sodium hydroxide $(\mathrm{NaOH})$, nickel chloride hexahydrate $\left(\mathrm{NiCl}_{2} \bullet 6 \mathrm{H}_{2} \mathrm{O}, 99.0 \%\right)$, sodium borohydride $\left(\mathrm{NaBH}_{4}\right.$, 99.0\%), chloroplatinic acid hexahydrate $\left(\mathrm{H}_{2} \mathrm{PtCl}_{6} \bullet 6 \mathrm{H}_{2} \mathrm{O}, 99.0 \%\right)$, perchloric acid $\left(\mathrm{HClO}_{4}, 70.0 \sim 72.0 \%\right)$, ethyl alcohol $\left(\mathrm{C}_{2} \mathrm{H}_{6} \mathrm{O}, 99.7 \%\right)$, ethylene glycol $\left(\mathrm{C}_{2} \mathrm{H}_{6} \mathrm{O}_{2}, 99.5 \%\right)$, and hydrochloric acid $(\mathrm{HCl}, 38.0 \%)$ were all obtained from Sinopharm Chemical Reagent Co., Ltd. (Beijing, China). All aqueous solutions were prepared using ultrapure water $\left(18.25 \mathrm{M} \Omega \mathrm{cm}^{-1}\right)$ purged by an ultrapure purification system (EPED-10TS, Chinese EPED Corporation).

\subsection{Preparation of Support and Catalysts}

B-ECP600 carbon black was prepared via a simple method using nickel as the medium and sodium borohydride as the boron source. A total of $430 \mathrm{mg}$ carbon black was mixed with $13.62 \mathrm{~g}$ $\mathrm{NiCl}_{2} \bullet 6 \mathrm{H}_{2} \mathrm{O} / \mathrm{EG}$ solution ( $\left.1 \mathrm{wt} \%\right), 130 \mathrm{~mL}$ ethylene glycol, $85 \mathrm{~mL}$ ultrapure water, and $1 \mathrm{~g}$ sodium hydroxide aqueous solution (10 wt \%). After being ultrasonically stirred for $1 \mathrm{~h}$, the mixture was heat-treated at $170{ }^{\circ} \mathrm{C}$ for $1 \mathrm{~h}$ in nitrogen atmosphere. A total of $3 \mathrm{~mL}$ hydrochloric acid and $20 \mathrm{~mL}$ EA were added when the mixture cooled to room temperature. The nickel-carbon was obtained after being washed with ultrapure water and dried at $60^{\circ} \mathrm{C}$ for $10 \mathrm{~h}$. Then, the nickel-carbon was dissolved into $250 \mathrm{~mL}$ ultrapure water and mixed with $5 \mathrm{~mL}$ prepared sodium borohydride aqueous solution (16.7 wt \%) under ultrasonic stirring until there were no bubbles in the solution. The B-ECP600 was finally obtained after being washed with ultrapure water and dried at $60^{\circ} \mathrm{C}$ for $10 \mathrm{~h}$.

Carbon-supported Pt nanoparticle catalysts (Pt/B-ECP600 and Pt/ECP600) were prepared via the conventional microwave method. First, $4.08 \mathrm{~g} \mathrm{H}_{2} \mathrm{PtCl}_{6} \bullet 6 \mathrm{H}_{2} \mathrm{O} / \mathrm{EG}$ solution (1.96 wt \%) was mixed with $70 \mathrm{mg}$ corresponding carbon support materials (B-ECP600 and ECP600), $21 \mathrm{~mL}$ EG, and $14 \mathrm{~mL}$ ultrapure water that was ultrasonically stirred for $1 \mathrm{~h}$, and then $1 \mathrm{~g}$ sodium hydroxide aqueous solution $(10 \mathrm{wt} \%)$ was added into the mixture and ultrasonically stirred for $10 \mathrm{~min}$. Next, the mixture was microwave-heated to $130^{\circ} \mathrm{C}$ from the initial temperature of $13{ }^{\circ} \mathrm{C}$, and then mixed with $0.3 \mathrm{~mL}$ hydrochloric acid and $5 \mathrm{~mL}$ EA. Pt nanoparticle catalysts supported by carbon were synthesized after being washed with ultrapure water and dried at $60^{\circ} \mathrm{C}$ for $10 \mathrm{~h}$. The total Pt loading was maintained at $30 \mathrm{wt} \%$ for catalysts.

\subsection{Physical Characterization}

The crystalline phase of the support materials and the catalysts was analyzed by recording their Power X-ray diffraction (PXRD) patterns on a Bruker D8 Advance diffractometer equipped with a $\mathrm{Cu}-\mathrm{K} \alpha$ radiation source. The images of transmission electron microscopy (TEM) were taken on a Tecnai F20 at an accelerating voltage of $200 \mathrm{KV}$. The X-ray photoelectron spectroscopy (XPS, ULVAC-PHI, Chigasaki, Japan) data were recorded by a PHI 5000 VersaProbe with an Al K $\alpha$ radiator at $5 \mathrm{kV}$. The nitrogen sorption isotherms of the B-ECP600 were collected at 77K by an ASAP 2020. Brunauer-Emmett-Teller (BET, Micromeritics, Norcross, GA, USA) was used for the specific surface area and porosity evaluations. A Fourier-transform infrared spectrometer (FTIR, NEXUS870, Nicolet, Madison, WI, USA) was used to identify the chemical structure functional groups contained in B-ECP600.

\subsection{Electrochemical Characterization}

All the electrochemical measurements were performed at a certain temperature $\left(30^{\circ} \mathrm{C}\right)$ with a three-electrode cell system provided by Gamry instruments. A glassy-carbon rotating disk electrode (RDE, Pine Research Instrumentation, diameter: $5 \mathrm{~mm}$, area: $0.196 \mathrm{~cm}^{2}$ ) was used as the working electrode, and a platinum wire was used as the counter electrode. A reversible hydrogen electrode (RHE) was used as the reference electrode in a $0.1 \mathrm{M} \mathrm{HClO}_{4}$ solution. Catalyst ink was made by mixing $2 \mathrm{mg}$ of catalyst with $1600 \mu \mathrm{L}$ ethanol, $400 \mu \mathrm{L}$ ultrapure, and $14.2 \mu \mathrm{L} 5 \mathrm{wt} \%$ Nafion. A total of 
$10 \mu \mathrm{L}$ of catalyst ink was dropped on the working electrode and dried under an incandescent lamp for $30 \mathrm{~s}$. The RHE zero potential was estimated with the potential at which the current crossed zero by measuring the steady-state polarization curves of the hydrogen electrode reactions in $0.1 \mathrm{M} \mathrm{HClO}_{4}$ saturated with $\mathrm{H}_{2}$. A cyclic voltammetry $(\mathrm{CV})$ measurement was performed in an $\mathrm{N}_{2}$-saturated $0.1 \mathrm{M}$ $\mathrm{HClO}_{4}$ solution at a scan rate of $50 \mathrm{mV} \cdot \mathrm{s}^{-1}$ ranging from 0.05 to $1.05 \mathrm{~V}$. The electrochemically active surface area (ECA) was calculated from the charge of hydrogen desorption between 0.05 and $0.4 \mathrm{~V}$ and corrected with the $\mathrm{Pt}$ capacity of $210 \mu \mathrm{C} \cdot \mathrm{cm}^{-2} \mathrm{Pt}$ [19]. The ORR polarization was performed in an $\mathrm{O}_{2}$-saturated $0.1 \mathrm{M} \mathrm{HClO}_{4}$ solution with a sweep rate of $10 \mathrm{mV} \mathrm{s}^{-1}$ and a rotation speed of $1600 \mathrm{rpm}$ at the temperature of $30{ }^{\circ} \mathrm{C}$. The accelerated durability tests (ADTs) were conducted in a $0.1 \mathrm{M} \mathrm{HClO}_{4}$ solution at a scan rate of $200 \mathrm{mV} \mathrm{s}^{-1}$, ranging from 0.6 to $1.0 \mathrm{~V}$ for 5000 cycles.

\section{Conclusions}

In this study, we successfully synthesized boron-doped ECP600 in a facile way and prepared catalysts with boron-doped ECP600 as the support. The structure of boron-doped ECP600 was investigated by TEM, XRD, BET specific surface area, FTIR, and XPS analyses. In addition, the structures and the electrochemical activities of Pt Pt/B-ECP600 and Pt/ECP600 were compared. Due to the boron-doping, Pt/B-ECP600 exhibits the better dispersion and the smaller size of Pt nanoparticles, and thus leads to much higher ECSA than Pt/ECP600. Additionally, the ORR activities of Pt/B-ECP600 were found to be remarkably higher than those of Pt-ECP600. The excellent ORR performance of $\mathrm{Pt} / \mathrm{B}-\mathrm{ECP} 600$ comes from the synergistic effect of the Pt nanoparticles and B-ECP600: on the one hand, boron oxides can promote the adsorption and dissociation of $\mathrm{O}_{2}$ on Pt. On the other hand, part of oxygen atoms on $\mathrm{Pt}$ may transport to the nearby $\mathrm{B}$ atoms for further reduction and thus enhance the efficiency of ORR. Moreover, B-ECP600 shows outstanding long-term stability in acidic solution compared with ECP600. To sum up, B-ECP600 is highly promising as a supporting material for PEMFCs, owing to its simple preparation process, enhanced-electrocatalytic activity, and the stability of the acidic environment when using B-ECP600 as the support.

Author Contributions: Conceptualization: J.G. and R.Y.; methodology: J.G. and R.Y.; formal analysis: J.G., R.Y., and H.H.; investigation: H.H.; writing-original draft preparation: R.Y.; writing-review and editing: T.Y.; supervision: J.G. and T.Y.; project administration: J.G. All authors have read and agreed to the published version of the manuscript.

Funding: This research was funded by the Fundamental Research Funds for the Central Universities, grant number 020414380168 .

Acknowledgments: The research was supported by Nanjing Doinpower Technology Co., Ltd.

Conflicts of Interest: The authors declare no conflict of interest.

\section{References}

1. Lu, Y.; Du, S.; Steinberger-Wilckens, R. One-dimensional nanostructured electrocatalysts for polymer electrolyte membrane fuel cells-A review. Appl. Catal. B Environ. 2016, 199, 292-314. [CrossRef]

2. Dey, S.; Mondal, B.; Chatterjee, S.; Rana, A.; Amanullah, S.; Dey, A. Molecular electrocatalysts for the oxygen reduction reaction. Nat. Rev. Chem. 2017, 1. [CrossRef]

3. Shao, M.; Chang, Q.; Dodelet, J.; Chenitz, R. Recent Advances in Electrocatalysts for Oxygen Reduction Reaction. Chem. Rev. 2016, 116, 3594-3657. [CrossRef] [PubMed]

4. Hu, J.; Kuttiyiel, K.; Sasaki, K.; Su, D.; Yang, T.; Park, G.; Zhang, C.; Chen, G.; Adzic, R. Pt Monolayer Shell on Nitrided Alloy Core-A Path to Highly Stable Oxygen Reduction Catalyst. Catalysts 2015, 5, 1321-1332. [CrossRef]

5. Shao, Y.; Cheng, Y.; Duan, W.; Wang, W.; Lin, Y.; Wang, Y.; Liu, J. Nanostructured Electrocatalysts for PEM Fuel Cells and Redox Flow Batteries: A Selected Review. ACS Catal. 2015, 5, 7288-7298. [CrossRef]

6. Zhou, X.; Qiao, J.; Yang, L.; Zhang, J. A Review of Graphene-Based Nanostructural Materials for Both Catalyst Supports and Metal-Free Catalysts in PEM Fuel Cell Oxygen Reduction Reactions. Adv. Energy Mater. 2014, 4, 1301523. [CrossRef] 
7. Zitolo, A.; Ranjbar-Sahraie, N.; Mineva, T.; Li, J.; Jia, Q.; Stamatin, S.; Harrington, G.F.; Lyth, S.M.; Krtil, P.; Mukerjee, S.; et al. Identification of catalytic sites in cobalt-nitrogen-carbon materials for the oxygen reduction reaction. Nat. Commun. 2017, 8, 957. [CrossRef]

8. Saputro, A.G.; Fajrial, A.K.; Maulana, A.L.; Fathurrahman, F.; Agusta, M.K.; Akbar, F.T.; Dipojono, H.K. Dissociative Oxygen Reduction Reaction Mechanism on the Neighboring Active Sites of a Boron-Doped Pyrolyzed Fe-N-C Catalyst. J. Phys. Chem. C 2020. [CrossRef]

9. Yang, D.; Gu, J.; Liu, X.; He, H.; Wang, M.; Wang, P.; Zhu, Y.; Fan, Q.; Huang, R. Monodispersed Pt3Ni Nanoparticles as a Highly Efficient Electrocatalyst for PEMFCs. Catalysts 2019, 9, 588. [CrossRef]

10. Zhu, J.; Lai, Q.; Zhao, Y.; Zhong, J.; Liang, Y. An effective $\mathrm{FeCl}_{3}$ template assisted synthesis of nitrogen, sulfur and iron-tridoped carbon nanosheets from a protic salt for oxygen reduction electrocatalysis. Chin. J. Catal. 2018, 39, 1453-1462. [CrossRef]

11. Zhao, H.; Hu, Z.; Zhu, Y.; Ge, L.; Yuan, Z. P-doped mesoporous carbons for high-efficiency electrocatalytic oxygen reduction. Chin. J. Catal. 2019, 40, 1366-1374. [CrossRef]

12. Yang, L.; Jiang, S.; Zhao, Y.; Zhu, L.; Chen, S.; Wang, X.; Wu, Q.; Ma, J.; Ma, Y.; Hu, Z. Boron-Doped Carbon Nanotubes as Metal-Free Electrocatalysts for the Oxygen Reduction Reaction. Angew. Chem. Int. Ed. 2011, 50, 7132-7135. [CrossRef] [PubMed]

13. Oh, J.; Park, S.; Jang, D.; Shin, Y.; Lim, D.; Park, S. Metal-free N-doped carbon blacks as excellent electrocatalysts for oxygen reduction reactions. Carbon 2019, 145, 481-487. [CrossRef]

14. Chen, S.; Chen, Z.; Siahrostami, S.; Higgins, D.; Nordlund, D.; Sokaras, D.; Kim, T.R.; Liu, Y.; Yan, X.; Nilsson, E.; et al. Designing Boron Nitride Islands in Carbon Materials for Efficient Electrochemical Synthesis of Hydrogen Peroxide. J. Am. Chem. Soc. 2018, 140, 7851-7859. [CrossRef] [PubMed]

15. Zhang, J.; Dai, L. Heteroatom-Doped Graphitic Carbon Catalysts for Efficient Electrocatalysis of Oxygen Reduction Reaction. ACS Catal. 2015, 5, 7244-7253. [CrossRef]

16. Nsabimana, A.; Bo, X.; Zhang, Y.; Li, M.; Han, C.; Guo, L. Electrochemical properties of boron-doped ordered mesoporous carbon as electrocatalyst and Pt catalyst support. J. Colloid Interface Sci. 2014, 428, 133-140. [CrossRef]

17. Cao, C.; Wei, L.; Zhai, Q.; Wang, G.; Shen, J. Biomass-derived nitrogen and boron dual-doped hollow carbon tube as cost-effective and stable synergistic catalyst for oxygen electroreduction. Electrochim. Acta 2017, 249, 328-336. [CrossRef]

18. Van Tam, T.; Kang, S.G.; Babu, K.F.; Oh, E.; Lee, S.G.; Choi, W.M. Synthesis of B-doped graphene quantum dots as a metal-free electrocatalyst for the oxygen reduction reaction. J. Mater. Chem. A 2017, 5, 10537-10543. [CrossRef]

19. Du, N.; Wang, C.; Long, R.; Xiong, Y. N-doped carbon-stabilized PtCo nanoparticles derived from Pt@ZIF-67: Highly active and durable catalysts for oxygen reduction reaction. Nano Res. 2017, 10, 3228-3237. [CrossRef]

20. Daems, N.; Sheng, X.; Vankelecom, I.F.; Pescarmona, P.P. Metal-free doped carbon materials as electrocatalysts for the oxygen reduction reaction. J. Mater. Chem. A 2014, 2, 4085-4110. [CrossRef]

21. Yu, D.; Nagelli, E.; Du, F.; Dai, L. Metal-Free Carbon Nanomaterials Become More Active than Metal Catalysts and Last Longer. J. Phys. Chem. Lett. 2010, 1, 2165-2173. [CrossRef]

22. Charreteur, F.; Jaouen, F.; Ruggeri, S.; Dodelet, J. Fe/N/C non-precious catalysts for PEM fuel cells: Influence of the structural parameters of pristine commercial carbon blacks on their activity for oxygen reduction. Electrochim. Acta 2008, 53, 2925-2938. [CrossRef]

23. Yang, Y.; Zhang, J.; Wu, X.; Fu, Y.; Wu, H.; Guo, S. Composites of boron-doped carbon nanosheets and iron oxide nanoneedles: Fabrication and lithium ion storage performance. J. Mater. Chem. A 2014, 2, 9111-9117. [CrossRef]

24. Xu, C.; Su, Y.; Liu, D. Three-dimensional N,B-doped graphene aerogel as a synergistically enhanced metal-free catalyst for the oxygen reduction reaction. Phys. Chem. Chem. Phys. 2015, 17, 25440-25448. [CrossRef]

25. Sun, D. Synthesis of Hierarchical Porous Carbons and Their Electrochemical Behavior. Ph.D. Thesis, Dalian University of Technology, Dalian, China, 2014.

26. Fellinger, T.; White, R.J.; Titirici, M.; Antonietti, M. Borax-Mediated Formation of Carbon Aerogels from Glucose. Adv. Funct. Mater. 2012, 22, 3254-3260. [CrossRef]

27. George, N.; Glavee, K.J.K.C.; Hadjapanayis, G.C. Borohydride Reductions of Metal Ions. A New Understanding of the Chemistry Leading to Nanoscale Particles of Metals, Borides, and Metal Borates. Langmuir 1992, 8, 771-773. 
28. He, D.; Zhang, L.; He, D.; Zhou, G.; Lin, Y.; Deng, Z.; Hong, X.; Wu, Y.; Chen, C.; Li, Y. Amorphous nickel boride membrane on a platinum-nickel alloy surface for enhanced oxygen reduction reaction. Nat. Commun. 2016, 7. [CrossRef]

29. Nesselberger, M.; Ashton, S.; Meier, J.C.; Katsounaros, I.; Mayrhofer, K.J.J.; Arenz, M. The Particle Size Effect on the Oxygen Reduction Reaction Activity of Pt Catalysts: Influence of Electrolyte and Relation to Single Crystal Models. J. Am. Chem. Soc. 2011, 133, 17428-17433. [CrossRef]

30. Mayrhofer, K.J.J.; Blizanac, B.B.; Arenz, M.; Stamenkovic, V.R.; Ross, P.N.; Markovic, N.M. The Impact of Geometric and Surface Electronic Properties of Pt-Catalysts on the Particle Size Effect in Electrocatalysis. J. Phys. Chem. B 2005, 109, 14433-14440. [CrossRef]

31. Sun, Y.; Dai, Y.; Liu, Y.; Chen, S. A rotating disk electrode study of the particle size effects of Pt for the hydrogen oxidation reaction. Phys. Chem. Chem. Phys. (PCCP) 2012, 14, 2278-2285. [CrossRef]

32. Stamenkovic, V.; Mun, B.S.; Mayrhofer, K.J.J.; Ross, P.N.; Markovic, N.M.; Rossmeisl, J.; Greeley, J.; Nørskov, J.K. Changing the Activity of Electrocatalysts for Oxygen Reduction by Tuning the Surface Electronic Structure. Angew. Chem. Int. Ed. 2006, 45, 2897-2901. [CrossRef] [PubMed]

33. Viswanathan, V.; Hansen, H.A.; Rossmeisl, J.; Nørskov, J.K. Universality in Oxygen Reduction Electrocatalysis on Metal Surfaces. ACS Catal. 2012, 2, 1654-1660. [CrossRef]

34. Zhang, S.; Chen, S. Enhanced-electrocatalytic activity of Pt nanoparticles supported on nitrogen-doped carbon for the oxygen reduction reaction. J. Power Sources 2013, 240, 60-65. [CrossRef]

35. Sun, S.; Zhang, G.; Geng, D.; Chen, Y.; Li, R.; Cai, M.; Sun, X. A Highly Durable Platinum Nanocatalyst for Proton Exchange Membrane Fuel Cells: Multiarmed Starlike Nanowire Single Crystal. Angew. Chem. Int. Ed. 2011, 50, 422-426. [CrossRef]

36. Lin, R.; Cai, X.; Zeng, H.; Yu, Z. Stability of High-Performance Pt-Based Catalysts for Oxygen Reduction Reactions. Adv. Mater. 2018, 30, 1705332. [CrossRef]

(C) 2020 by the authors. Licensee MDPI, Basel, Switzerland. This article is an open access article distributed under the terms and conditions of the Creative Commons Attribution (CC BY) license (http://creativecommons.org/licenses/by/4.0/). 